\title{
CASCA DE ARROZ E ESTERCO BOVINO COMO SUBSTRATOS PARA A MULTIPLICAÇÃO DE MINHOCAS E PRODUÇÃO DE MUDAS DE TOMATE E ALFACE
}

\author{
Gerusa Pauli Kist Steffen ${ }^{1}$, Zaida Inês Antoniolli' ${ }^{1}$, Ricardo Bemfica \\ STEFFEN $^{1}$ \& Rafael Goulart MACHADO ${ }^{2}$ \\ ${ }^{1}$ Departamento de Solos, Universidade Federal de Santa Maria, Av. Roraima, n.1000, CEP: $97105-$ \\ 900, Santa Maria, RS, Brasil. E-mail: ge.pauli@yahoo.com.br \\ ${ }^{2}$ Curso de Agronomia, Universidade Federal de Santa Maria, Centro de Ciências Rurais, Av. Roraima, \\ n.1000, CEP: 97105-900, Santa Maria, RS, Brasil.
}

Steffen, G. P. K., Z. I. Antoniolli, R. B. Steffen \& R. G. Machado. 2010. Casca de arroz e esterco bovino como substratos para a multiplicação de minhocas e produção de mudas de tomate e alface. Acta Zoológica Mexicana (n.s.), Número Especial 2: 333-343.

RESUMO. Para que um substrato seja considerado ideal para a produção de mudas, deve reunir atributos que assegurem a germinação das sementes e satisfatório desenvolvimento das plantas. O presente trabalho teve como objetivos a produção de vermicompostos e sua utilização na produção de mudas de alface e tomateiro. Primeiramente, foram produzidos cinco diferentes vermicompostos com a inoculação de Eisenia andrei Bouché, 1972 em substratos à base de esterco curtido de bovinos, casca de arroz carbonizada e natural. Aos 60 dias após a instalação do experimento avaliou-se o número de minhocas jovens, adultas e casulos, bem como o índice de multiplicação e a biomassa de minhocas frescas e secas. Posteriormente, os vermicompostos obtidos foram misturados com diferentes proporções de solo e avaliados quanto à eficiência como substratos orgânicos na produção das mudas. As mudas das espécies olerícolas foram avaliadas quanto à altura, número de folhas e fitomassa fresca e seca aos 30 e 45 dias após a semeadura para alface e tomateiro respectivamente. Observou-se que a adição de casca de arroz natural ao esterco bovino, nas proporções de 25 e $50 \%$, é eficiente na multiplicação de minhocas. Para o cultivo do tomateiro, os substratos à base de vermicompostos apresentaram resultados equivalentes ou superiores ao substrato comercial testado.

Palavras chave: Eisenia andrei, húmus, produção vegetal.

Steffen, G. P. K., Z. I. Antoniolli, R. B. Steffen \& R. G. Machado. 2010. Cáscara de arroz y estiércol bovino como sustratos para la multiplicación de lombrices de tierra y la producción de plántulas de tomate y lechuga. Acta Zoológica Mexicana (n.s.), Número Especial 2: 333-343.

RESUMEN. Para que un substrato sea considerado ideal para la producción de plántulas, debe reunir atributos que aseguren la germinación de las semillas y el satisfactorio desarrollo de las plantas. El presente trabajo tuvo como objetivo la producción de vermicomposta y su utilización en la producción de plántulas de lechuga y jitomate. Primeramente, fueron producidos cinco diferentes vermicompostas con la inoculación de Eisenia andrei Bouché, 1972 en substratos a base de estiércol curtido de bovinos,

Recibido: 16/05/2008; aceptado: 08/01/2010. 
Steffen et al.: Casca de arroz como sustrato na multiplicação de minhocas

cáscara de arroz carbonizada y natural. A los 60 días de la instalación del experimento, se evaluó el número de lombrices jóvenes, adultas y capullos, bien como el índice de multiplicación y la biomasa de lombrices frescas y secas. Posteriormente, las vermicompostas obtenidas fueron mezcladas con diferentes proporciones de suelo y evaluadas cuanto a la eficacia como substratos orgánicos en la producción de plántulas. Se evaluaron la altura, números de hojas y biomasa fresca y seca de las plantas a los 30 y 45 días después de la siembra para la lechuga y el jitomate, respectivamente. Se observo que la adición de la cáscara de arroz natural al estiércol bovino, en las proporciones de 25 y $50 \%$, es eficiente en la multiplicación de lombrices. Para el cultivo del jitomate, los substratos a base de vermicomposta presentaron resultados equivalentes o superiores al substrato comercial testado.

Palabras clave: Eisenia andrei, humus, producción vegetal

\section{INTRODUÇÃO}

A escolha de um substrato hortícola deve ser baseada em dois critérios essenciais: o custo de aquisição e a disponibilidade do material para produção do substrato. $\mathrm{O}$ mesmo deve apresentar custo baixo e estar disponível em grande quantidade (Andriolo 1999). A decisão por um ou outro material dependerá, além das necessidades da cultura de interesse, do custo e da disponibilidade do material.

Nos últimos anos, a casca de arroz passou a ser intensamente utilizada como substrato para o crescimento de plantas, por apresentar elevada disponibilidade e características favoráveis ao desenvolvimento vegetal. No ano agrícola 2006/07, o Brasil produziu mais de 11 milhões de toneladas de arroz em casca (Oliveira 2007). O Estado do Rio Grande do Sul, na safra de 2005/06, produziu 6.861.460 toneladas de arroz em casca (Fagundes et al. 2007), o que representa mais de 1.300 .000 toneladas de casca de arroz. Este resíduo gerado após o beneficiamento do arroz, normalmente é queimado nos engenhos para a secagem dos grãos ou abandonado em lavouras e beira de estradas (Foletto et al. 2005), sendo subutilizado em outras atividades.

A casca de arroz pode ser utilizada como substrato tanto na forma natural quanto carbonizada, misturada a outros materiais. Apresenta baixa capacidade de retenção de água, drenagem rápida e eficiente, proporcionando boa oxigenação para as raízes, elevado espaço de aeração ao substrato, resistência à decomposição, relativa estabilidade de estrutura, baixa densidade e $\mathrm{pH}$ próximo à neutralidade (Mello 2006). A adição de casca de arroz carbonizada a outros materiais constitui um importante aliado na melhoria das propriedades físicas do substrato final (Couto et al. 2003).

O vermicomposto ou húmus, composto estável obtido a partir da transformação de resíduos orgânicos com minhocas, apresenta alto valor nutricional para as plantas (Hand et al. 1988) e é rico em bactérias e microrganismos promotores do crescimento das plantas (Domínguez et al., este número). O vermicomposto funciona como um bioestimulador do crescimento vegetal, atuando de forma benéfica no desenvolvimento das plantas (Edwards 2004, Domínguez et al., este número).

A utilização de vermicomposto em substratos olerícolas, em $75 \%$ do volume do substrato, é uma prática viável na produção de mudas de alface e repolho (Menezes 
1998). Milec et al. (2007), comparando a eficiência do substrato comercial Germina Plant ${ }^{\circledR}$ com e sem adubação de base com dois substratos orgânicos constituídos por vermicomposto bovino ou suíno $(75 \%)$ + casca de arroz carbonizada $(25 \%)$, observou que as mudas de couve brócolis Santana tiveram maior altura e diâmetro do caule nos substratos à base de vermicomposto que no substrato comercial sem adubação.

Outro aspecto relevante da produção de húmus é a multiplicação de minhocas, visando a comercialização das matrizes. Pesquisas envolvendo minhocas estão focadas em dois pontos principais: 1) a conversão de diversos resíduos vegetais e animais em húmus, que adicionado aos campos agrícolas melhorem a estrutura e a fertilidade do solo, além da sua utilização como substrato comercial na produção de espécies olerícolas; e 2) o uso de minhocas como suplementos protéicos para aves, peixes e suínos, por serem excelentes fontes de proteínas e vitaminas (Edwards \& Fletcher 1988, Edwards 2004).

Neste sentido, o presente trabalho teve como objetivos: 1) determinar a eficiência de substratos constituídos por esterco curtido de bovinos, casca de arroz natural e carbonizada na multiplicação e desenvolvimento de Eisenia andrei Bouché, 1972 e 2) verificar a possibilidade de utilização dos substratos (vermicompostos) estudados na produção de mudas de alface cultivar Regina e tomate cultivar Gaúcho.

\section{MATERIAL E MÉTODOS}

O estudo foi realizado em casa de vegetação do Departamento de Solos da Universidade Federal de Santa Maria (UFSM).

\section{Produção de minhocas em diferentes substratos}

Os materiais utilizados como substrato para a multiplicação de minhocas foram: casca de arroz natural (CAN), casca de arroz carbonizada (CAC) e esterco curtido de bovinos (EB), sendo os tratamentos definidos pela combinação de diferentes proporções de casca de arroz e esterco de bovinos. Os tratamentos avaliados foram: 1) casca de arroz carbonizada $50 \%$ e esterco bovino $50 \%$ (CAC50EB50); 2) casca de arroz carbonizada $25 \%$ e esterco bovino $75 \%$ (CAC25EB75); 3 ) casca de arroz natural $50 \%$ e esterco bovino 50\% (CAN50EB50); 4) casca de arroz natural $25 \%$ e esterco bovino 75\% (CAN25EB75) e 5) esterco bovino 100\% (EB100). A mistura do esterco com o resíduo do beneficiamento do arroz foi realizada com base no volume seco.

As unidades experimentais foram sacos plásticos pretos com capacidade para oito litros. Nestes foram adicionados quatro litros do substrato correspondente a cada tratamento e seis minhocas adultas (cliteladas) da espécie $E$. andrei, que apresenta alta capacidade de proliferação, crescimento rápido, elevada resistência e adaptabilidade às condições de cativeiro (Aquino \& Nogueira 2001). As minhocas foram 
obtidas de uma população pura mantida no minhocário do Departamento de Solos da UFSM.

Após 60 dias da instalação do experimento, avaliou-se a população de minhocas, o número de indivíduos jovens e adultos, o número de casulos, a biomassa de minhocas frescas e secas e o índice de multiplicação das minhocas. A população de minhocas, assim como o número de casulos, foram obtidos por contagem manual. Os indivíduos coletados em cada unidade experimental foram colocados em frascos com água limpa, onde permaneceram por 24 horas para a eliminação do conteúdo presente em seu trato digestivo. Posteriormente, as minhocas foram secas em papel toalha e pesadas para a obtenção da sua biomassa fresca. Após a pesagem, foram mantidas em estufa a $60^{\circ} \mathrm{C}$, em frascos plásticos forrados com papel alumínio, durante 72 horas. Em seguida, as amostras foram retiradas da estufa, levadas ao laboratório e mantidas em dessecador até peso constante a fim de serem pesadas para a obtenção da biomassa seca.

Para o cálculo do índice de multiplicação das minhocas, utilizou-se a fórmula (IM $=\mathrm{Pf} / \mathrm{Pi}$, onde $\mathrm{Pf}=$ população final de minhocas e $\mathrm{Pi}=$ população inicial de minhocas, correspondente ao número de matrizes inoculadas).

$\mathrm{O}$ delineamento experimental utilizado foi o inteiramente casualisado com cinco repetições. Os dados obtidos foram transformados para raiz quadrada de $\mathrm{x}+0,5$ e a análise estatística e o teste de médias foram realizados pelo teste de Scott-Knott a $5 \%$ de probabilidade de erro, utilizando-se o programa estatístico SISVAR (Ferreira 2000).

Em seguida, os substratos produzidos pelo processo de vermicompostagem foram secos ao ar, peneirados e armazenados em sacos plásticos para posterior avaliação da eficiência destes substratos na produção de mudas de alface e de tomate. Para a avaliação da fertilidade química dos vermicompostos, determinaram-se os teores de macro e micronutrientes e o potencial de hidrogênio em cada substrato.

\section{Produção de mudas de alface e tomate com diferentes substratos}

A segunda etapa do experimento foi realizada em casa de vegetação do Departamento de Solos da UFSM. Os substratos avaliados quanto ao desenvolvimento das mudas de alface cultivar Regina e tomate cultivar Gaúcho constaram de duas proporções de solo $(25$ e $50 \% \mathrm{v} / \mathrm{v})$ e os cinco vermicompostos obtidos na primeira etapa do experimento (Tabela I), comparadas com um substrato comercial (turfa fértil). Os tratamentos avaliados foram: CAC50EB50(75) + Solo(25), CAC50EB50(75) + Solo(50), CAC25EB75(75) + Solo(25), CAC25EB75(50) + Solo(50), CAN50EB50(75) + Solo(25), CAN50EB50(50) + Solo(50), CAN25EB75(75) + Solo(25), CAN25EB75(50) $+\operatorname{Solo}(50), \operatorname{EB} 100(75)+\operatorname{Solo}(25), \operatorname{EB} 100(50)+\operatorname{Solo}(50)$ e a turfa fértil. 
Tabela I. Características químicas do solo e dos substratos à base de casca de arroz e esterco bovino produzidos com o auxílio de minhocas E. andrei.

\begin{tabular}{lccccccc}
\hline \multirow{2}{*}{ Tratamento* } & MO (\%) & pH água 1:1 & $\mathrm{P}$ & $\mathrm{K}$ & $\mathrm{Ca}$ & $\mathrm{Mg}$ & $\mathrm{CTC}$ \\
\cline { 4 - 7 } & & & & $----\mathrm{mg} \mathrm{dm}^{-3}$--- & & ------Cmol $\mathrm{dm}^{-3}$------- \\
\hline CAC50EB50 & 7,3 & 6,9 & 76 & 800 & 8,9 & 5,6 & 17,7 \\
CAC25EB75 & 8,6 & 7,0 & 76 & 800 & 9,8 & 6,2 & 19,0 \\
CAN50EB50 & 13,9 & 7,8 & 76 & 800 & 10,6 & 6,7 & 20,1 \\
CAN25EB75 & 14,1 & 7,8 & 76 & 800 & 11,9 & 6,9 & 21,6 \\
EB100 & 12,3 & 8,0 & 76 & 800 & 11,3 & 7,0 & 20,9 \\
Solo & 1,6 & 5,2 & 4,7 & 104 & 3,2 & 1,0 & 4,6 \\
\hline
\end{tabular}

*CAC50EB50 = casca de arroz carbonizada 50\% e esterco bovino 50\%, CAC25EB75 = casca de arroz carbonizada $25 \%$ e esterco bovino $75 \%$, CAN50EB50 = casca de arroz natural $50 \%$ e esterco bovino $50 \%$, CAN25EB $75=$ casca de arroz natural $25 \%$ e esterco bovino $75 \%$, EB100 = esterco bovino $100 \%$.

O solo utilizado no experimento foi classificado como Argissolo Vermelho distrófico típico (Embrapa 1999), estando localizado na área experimental do Departamento de Solos da UFSM. O solo foi coletado em parcelas experimentais que vinham sendo continuamente cultivadas sob plantio direto, com histórico de adubação e calagem.

As sementes das duas espécies hortícolas foram semeadas em bandejas de isopor de 258 alvéolos, as quais foram mantidas em sistema "float" durante a condução do experimento. As bandejas ficaram protegidas com uma tela para evitar a interferência de predadores. As sementes utilizadas foram inicialmente desinfestadas com hipoclorito de sódio 0,5\% durante 25 segundos (Fernandez 1993). Em seguida, foram lavadas com água destilada durante um minuto para a retirada do residual de hipoclorito de sódio e mantidas em papel de germinação a $26^{\circ} \mathrm{C}$, no escuro por quatro dias. $\mathrm{O}$ transplante das plântulas para as bandejas ocorreu quando estas apresentavam radícula de aproximadamente $2 \mathrm{~mm}$ de comprimento. Foram transplantadas duas plântulas por alvéolo e o desbaste ocorreu dez dias após o transplante. No decorrer do estudo, as mudas não receberam adição de fertilizante.

Avaliou-se a altura das mudas, o número de folhas e a fitomassa fresca e seca da parte aérea de ambas as espécies. As mudas de tomate foram avaliadas 45 dias após o transplante, enquanto que as mudas de alface foram avaliadas aos 30 dias. As mudas foram cuidadosamente retiradas dos alvéolos, avaliadas quanto à altura e número de folhas, sendo posteriormente pesadas para a obtenção da fitomassa fresca. Em seguida, foram colocadas em sacos de papel devidamente identificados e mantidas em estufa a $60^{\circ} \mathrm{C}$, durante 48 horas para a obtenção da fitomassa seca.

$\mathrm{O}$ delineamento experimental utilizado foi o inteiramente casualizado com cinco repetições. Os dados de altura, número de folhas, fitomassa fresca e seca das mudas de tomate e alface foram transformados para raiz de $\mathrm{x}+0,5$ e a análise estatística e $\mathrm{o}$ 
teste de médias foram realizados pelo teste de Scott-Knott a 5\% de probabilidade de erro, utilizando-se o programa estatístico SISVAR (Ferreira 2000).

\section{RESULTADOS}

Os tratamentos esterco bovino puro e esterco bovino acrescido de 25 ou $50 \%$ de casca de arroz natural constituíram bons substratos para a multiplicação e o desenvolvimento da $E$. andrei. A maior incidência de minhocas jovens foi observada nos tratamentos CAN50EB50, CAN25EB75 e EB100, sendo o maior número de minhocas (269) encontrado no tratamento constituído por proporções iguais de esterco bovino e casca de arroz natural (Tabela II). Quanto ao número de minhocas adultas, os melhores resultados foram obtidos nos tratamentos CAN25EB75 e EB100, os quais diferiram estatisticamente dos demais, sendo encontradas 28 e 23 minhocas adultas respectivamente (Tabela II). O maior índice de multiplicação (48 vezes) foi verificado no tratamento onde houve adição de $50 \%$ de casca de arroz natural ao esterco bovino (Tabela II). No tratamento EB100, o índice de multiplicação foi de 38 vezes, um valor intermediário entre os índices dos tratamentos com casca de arroz natural (mais altos) e casca de arroz carbonizada (mais baixos).

Não houve diferença significativa entre os tratamentos avaliados quanto à produção de casulos. No entanto, o maior número (71) foi encontrado no tratamento constituído por CAN25EB75, e o menor número de casulos (46) verificado no tratamento CAN50EB50 (Tabela II).

Os maiores valores de biomassa fresca e seca de minhocas foram obtidos nos tratamentos onde houve adição de casca de arroz natural ao esterco e no tratamento EB100, os quais não diferiram estatisticamente entre si (Tabela II). O maior valor de

Tabela II. Número de minhocas e casulos, índice de multiplicação e massa fresca e seca de minhocas, nos tratamentos à base de casca de arroz carbonizada (CAC), casca de arroz natural (CAN) e esterco bovino (EB) em diferentes proporções. Média de quatro repetições.

\begin{tabular}{lcccccccc}
\hline \multirow{2}{*}{ Tratamento } & \multicolumn{2}{c}{ Número de minhocas } & Casulos & \multicolumn{2}{c}{$\begin{array}{c}\text { Índice de } \\
\text { multiplicação }\end{array}$} & \multicolumn{2}{c}{ Massa de minhocas $(\mathrm{g})$} \\
\cline { 2 - 4 } \cline { 8 - 9 } & Jovens & Adultas & Total & & & & fresca & seca \\
\hline CAC50EB50 & $137 \mathrm{~b}^{1}$ & $13 \mathrm{~b}$ & $150 \mathrm{c}$ & $47 \mathrm{a}$ & $25,00 \mathrm{c}$ & $13,86 \mathrm{~b}$ & $1,72 \mathrm{~b}$ \\
CAC25EB75 & $100 \mathrm{~b}$ & $12 \mathrm{~b}$ & $112 \mathrm{c}$ & $56 \mathrm{a}$ & $18,66 \mathrm{c}$ & $12,64 \mathrm{~b}$ & $1,78 \mathrm{~b}$ \\
CAN50EB50 & $269 \mathrm{a}$ & $19 \mathrm{~b}$ & $288 \mathrm{a}$ & $46 \mathrm{a}$ & $48,00 \mathrm{a}$ & $26,03 \mathrm{a}$ & $3,62 \mathrm{a}$ \\
CAN25EB75 & $237 \mathrm{a}$ & $28 \mathrm{a}$ & $265 \mathrm{a}$ & $71 \mathrm{a}$ & & $44,16 \mathrm{a}$ & $23,74 \mathrm{a}$ & $3,23 \mathrm{a}$ \\
EB100 & $205 \mathrm{a}$ & $23 \mathrm{a}$ & $228 \mathrm{~b}$ & $56 \mathrm{a}$ & $38,00 \mathrm{~b}$ & $29,99 \mathrm{a}$ & $3,50 \mathrm{a}$ \\
CV (\%) & 10,95 & 13,28 & 9,93 & 19,02 & 9,75 & 12,11 & 14,56 \\
\hline
\end{tabular}

${ }^{1}$ Médias seguidas da mesma letra nas colunas não diferem entre si pelo teste de Scott-Knott a $5 \%$ de probabilidade.

${ }^{2}$ Para explicação dos tratamentos, favor ver nota no pé da Tabela I.

3 Índice de multiplicação $=\left(\mathrm{N}^{\circ}\right.$ total de minhocas $) /\left(\mathrm{N}^{\circ}\right.$ de minhocas inoculadas $)$. 
biomassa de minhocas secas $(3,62 \mathrm{~g})$ foi verificado no tratamento CAN50EB50 e o menor valor $(1,72 \mathrm{~g})$, no tratamento CAC50EB50.

A adição de casca de arroz carbonizada foi significativamente menos eficiente do que a adição de casca de arroz natural em todos os parâmetros avaliados no experimento. Neste caso, evidenciou-se utilização preferencial de casca de arroz natural, nas proporções de 25 ou $50 \%$ juntamente com esterco bovino, ao invés de casca de arroz carbonizada (Tabela II).

Para a produção de alface, observou-se que as mudas cultivadas nos substratos CAC50EB50(50) + Solo(50), CAC25EB75(75) + Solo(25), CAC25EB75(50) + Solo (50), CAN25EB75(75) + Solo(25), CAN25EB75(50) + Solo(50), EB100(50) + Solo(50) e o substrato turfa fértil não apresentaram diferenças significativas quanto à altura da planta, número de folhas e fitomassa fresca e seca, mas foram superiores aos demais substratos analisados quanto à altura da muda (Tabela III). Não houve diferença significativa entre os parâmetros número de folhas e fitomassa fresca e seca em todos os substratos avaliados. No entanto, o substrato constituído por CAC50EB50(50) + Solo(50) apresentou valor médio de fitomassa fresca superior aos demais tratamentos, 248,60 mg (Tabela III).

Tabela III. Altura (mm), número de folhas e fitomassa fresca e seca $(\mathrm{mg})$ de mudas de alface cultivar Regina cultivadas em bandejas contendo diferentes vermicompostos à base de casca de arroz natural (CAN), casca de arroz carbonizada (CAC), esterco bovino (EB) misturados com diferentes proporções de solo, em casa de vegetação, durante 30 dias. Média de cinco repetições.

\begin{tabular}{lccrr}
\hline Tratamento & $\begin{array}{c}\text { Altura da planta } \\
(\mathrm{mm})\end{array}$ & Número de folhas & \multicolumn{2}{c}{$\begin{array}{c}\text { Fitomassa } \\
(\mathrm{mg})\end{array}$} \\
\cline { 4 - 5 } & & & fresca & seca \\
\hline CAC50EB50(75)+Solo(25) & $102,40 \mathrm{a}^{1}$ & $5 \mathrm{a}$ & $248,60 \mathrm{a}$ & $10,80 \mathrm{a}$ \\
CAC50EB50(75)+Solo(50) & $88,40 \mathrm{~b}$ & $5 \mathrm{a}$ & $182,60 \mathrm{a}$ & $9,00 \mathrm{a}$ \\
CAC25EB75(75)+Solo(25) & $94,20 \mathrm{a}$ & $5 \mathrm{a}$ & $184,00 \mathrm{a}$ & $8,60 \mathrm{a}$ \\
CAC25EB75(50)+Solo(50) & $94,40 \mathrm{a}$ & $5 \mathrm{a}$ & $202,00 \mathrm{a}$ & $9,20 \mathrm{a}$ \\
CAN50EB50(75)+Solo(25) & $77,80 \mathrm{~b}$ & $5 \mathrm{a}$ & $148,40 \mathrm{a}$ & $7,40 \mathrm{a}$ \\
CAN50EB50(50)+Solo(50) & $85,80 \mathrm{~b}$ & $5 \mathrm{a}$ & $167,00 \mathrm{a}$ & $8,00 \mathrm{a}$ \\
CAN25EB75(75)+Solo(25) & $100,40 \mathrm{a}$ & $5 \mathrm{a}$ & $231,80 \mathrm{a}$ & $11,00 \mathrm{a}$ \\
CAN25EB75(50)+Solo(50) & $94,80 \mathrm{a}$ & $5 \mathrm{a}$ & $187,20 \mathrm{a}$ & $9,00 \mathrm{a}$ \\
EB100(75)+Solo(25) & $85,80 \mathrm{~b}$ & $5 \mathrm{a}$ & $212,00 \mathrm{a}$ & $10,60 \mathrm{a}$ \\
EB100(50)+Solo(50) & $98,60 \mathrm{a}$ & $5 \mathrm{a}$ & $203,20 \mathrm{a}$ & $10,00 \mathrm{a}$ \\
Substrato turfa fértil & $93,20 \mathrm{a}$ & $5 \mathrm{a}$ & $232,20 \mathrm{a}$ & $7,60 \mathrm{a}$ \\
CV (\%) & 5,55 & 4,31 & 12,00 & 11,17 \\
\hline
\end{tabular}

${ }^{1}$ Médias seguidas da mesma letra nas colunas não diferem entre si pelo teste de Scott-Knott a $5 \%$ de probabilidade de erro.

${ }^{2}$ Para explicação dos tratamentos, favor ver nota no pé da Tabela I. 
As mudas de tomateiro cultivadas no substrato CAC50EB50(75) Solo(25) apresentaram maior altura e fitomassa fresca e seca 45 dias após a semeadura (Tabela IV), não apresentando diferença significativa quanto ao número de folhas. O substrato comercial turfa fértil teve altura e fitomassa inferior aos tratamentos CAC50EB50(75) + Solo(25), CAC50EB50(50) + Solo(50) e CAC25EB75(75) + Solo(25), e fitomassa, menor que o tratamento EB100(50) + Solo(50) (Tabela IV). Os demais tratamentos [CAC25EB75(50) + Solo(50), CAN50EB50(75) + Solo(25), CAN50EB50(50) + Solo(50), CAN25EB75(75) + Solo(25) e CAN25EB75(50) + Solo(50)] também apresentaram resultados inferiores e não significativamente diferentes da turfa fértil (Tabela IV).

\section{DISCUSSÃO}

A utilização de resíduo do beneficiamento do arroz, especialmente casca de arroz natural ao esterco bovino, nas proporções avaliadas neste experimento, favoreceu a atividade reprodutiva da $E$. andrei. O maior índice de multiplicação ocorreu no tratamento com adição de $50 \%$ de casca de arroz natural, provavelmente devido à casca de arroz proporcionar um aumento da aeração e redução da densidade do substrato. Estes resultados corroboram com os encontrados por Morselli et al. (1997), que,

Tabela IV. Altura (mm), número de folhas e fitomassa fresca e seca $(\mathrm{mg})$ de mudas de tomateiro cultivadas em bandejas contendo diferentes vermicompostos à base de casca de arroz natural (CAN), casca de arroz carbonizada (CAC), esterco bovino (EB) misturados com diferentes proporções de solo, em casa de vegetação, durante 45 dias. Média de quatro repetições.

\begin{tabular}{lcccc}
\hline Tratamento & $\begin{array}{c}\text { Altura da planta } \\
(\mathrm{mm})\end{array}$ & $\begin{array}{c}\text { Número de folhas } \\
\text { fresca }\end{array}$ & \multicolumn{2}{c}{$\begin{array}{c}\text { Fitomassa } \\
(\mathrm{mg})\end{array}$} \\
\cline { 4 - 5 } & & & $393,25 \mathrm{a}$ & $35,00 \mathrm{a}$ \\
CAC50EB50(75)+Solo(25) & $99,25 \mathrm{a}^{1}$ & $5 \mathrm{a}$ & $248,75 \mathrm{~b}$ & $22,00 \mathrm{~b}$ \\
CAC50EB50(75)+Solo(50) & $75,75 \mathrm{~b}$ & $4 \mathrm{a}$ & $283,00 \mathrm{~b}$ & $25,50 \mathrm{~b}$ \\
CAC25EB75(75)+Solo(25) & $84,50 \mathrm{~b}$ & $4 \mathrm{a}$ & $153,50 \mathrm{c}$ & $13,75 \mathrm{c}$ \\
CAC25EB75(50)+Solo(50) & $64,25 \mathrm{c}$ & $4 \mathrm{a}$ & $184,50 \mathrm{c}$ & $15,50 \mathrm{c}$ \\
CAN50EB50(75)+Solo(25) & $64,00 \mathrm{c}$ & $4 \mathrm{a}$ & $123,25 \mathrm{c}$ & $10,50 \mathrm{c}$ \\
CAN50EB50(50)+Solo(50) & $54,75 \mathrm{c}$ & $4 \mathrm{a}$ & $198,75 \mathrm{c}$ & $16,75 \mathrm{c}$ \\
CAN25EB75(75)+Solo(25) & $70,25 \mathrm{c}$ & $4 \mathrm{a}$ & $194,75 \mathrm{c}$ & $17,25 \mathrm{c}$ \\
CAN25EB75(50)+Solo(50) & $67,00 \mathrm{c}$ & $4 \mathrm{a}$ & $234,50 \mathrm{~b}$ & $19,00 \mathrm{c}$ \\
EB100(75)+Solo(25) & $75,50 \mathrm{c}$ & $4 \mathrm{a}$ & $297,25 \mathrm{~b}$ & $25,50 \mathrm{~b}$ \\
EB100(50)+Solo(50) & $79,75 \mathrm{c}$ & $4 \mathrm{a}$ & $131,00 \mathrm{c}$ & $11,00 \mathrm{c}$ \\
Substrato turfa fértil & $61,25 \mathrm{c}$ & $4 \mathrm{a}$ & 13,42 & 16,48 \\
CV (\%) & 7,31 & 1,15 & & \\
\hline
\end{tabular}

${ }^{1}$ Médias seguidas da mesma letra nas colunas não diferem entre si pelo teste de Scott-Knott a $5 \%$ de probabilidade de erro.

${ }^{2}$ Para explicação dos tratamentos, favor ver nota no pé da Tabela I. 
avaliando a capacidade reprodutiva e o desenvolvimento de $E$. fetida em substratos constituídos por diferentes proporções de esterco, bagaço de laranja, verduras e casca de arroz, verificaram que o desenvolvimento das minhocas foi superior quando casca de arroz foi adicionada aos demais substratos.

As proporções de esterco bovino de 50, 75 e 100\% foram mais eficientes na multiplicação de minhocas, mas somente quando se utilizou casca de arroz natural e não casca de arroz carbonizada. Pereira et al. (2005) também observaram que os substratos com 75 e $100 \%$ de esterco bovino (misturados com palha de carnaúba) proporcionaram maior atividade reprodutiva das minhocas da espécie E. fetida. Contudo, os resultados obtidos nessa mistura foram muito inferiores aos encontrados no presente trabalho; sessenta e dois dias após a inoculação de 50 minhocas, os autores observaram índice de multiplicação de apenas 2 vezes (comparado com $>12$ vezes no atual estudo).

A avaliação da biomassa fresca de minhocas, parâmetro que avalia o desenvolvimento dos organismos fornece uma informação importante para os minhocultores que visam a comercialização das minhocas como fonte de alimento para animais. Neste sentido, sugere-se que o substrato que produzir um maior número de indivíduos, bem como indivíduos com maior biomassa fresca (nesse caso CAN50EB50), seja o mais indicado para ser utilizado na criação de minhocas.

A utilização de casca de arroz como substrato na minhocultura pode ser uma boa alternativa para os produtores de minhocas que encontram dificuldade em obter grande quantidade de esterco para ser utilizado na atividade. Como o resíduo do arroz apresenta alta disponibilidade e reduzido custo no Estado do Rio Grande do Sul, seu uso na minhocultura pode ser indicado, visto que, nas proporções avaliadas neste estudo, foi eficiente para a multiplicação das minhocas, além de aumentar o volume de substrato quando houver pouca disponibilidade de esterco ou outros materiais orgânicos.

As mudas de alface cultivar Regina atingiram padrão comercialmente aceito quando produzidas em todos os substratos analisados neste estudo e as mudas de tomate cultivar Gaúcho, quando produzidas no substrato composto por $25 \%$ de solo e $75 \%$ de húmus constituído à base de $50 \%$ de casca de arroz carbonizada e $50 \%$ de solo.

Substratos com elevado teor de matéria orgânica asseguram um elevado número de espaços porosos, além de uma baixa densidade aparente. A porosidade é um fator muito importante para o pleno desenvolvimento das plantas, capaz de proporcionar aeração e drenagem adequadas, tornando o substrato estruturado e com maior capacidade de retenção de água (Diniz et al. 2006). Nesse sentido, no presente experimento o uso de maiores proporções de vermicomposto e menos solo nos substratos, resultou em melhores crescimentos de alface (Tabela III). No caso do tomate, o uso do húmus produzido com casca de arroz carbonizada foi mais eficaz para aumentar o crescimento da planta, especialmente quando ele foi adicionado em maior proporção $(75 \%)$ e produzido misturado com esterco bovino (50\%) (Tabela IV). 
O crescimento da alface no presente estudo foi melhor que observado por Santos (2000) em cultivo hidropônico, indicando os benefícios do uso do vermicomposto para a produção de mudas. Contudo, Diniz et al. (2006) encontraram melhor crescimento da alface (cultivares Lucy Brown e Vera), com o substrato comercial Plantmax ${ }^{\circledR}$, em comparação com húmus puro de minhocas (proveniente de torta de filtro de cana-de-açúcar). Mas, quando o húmus foi misturado com vermiculita em diferentes proporções $(0,10,20$ e $40 \%)$, o tratamento húmus $+40 \%$ de vermiculita obteve resultados similares aos do Plantmax ${ }^{\circledR}$. Esses mesmos autores também observaram resultados similares com o tomateiro cultivar Santa Clara (menor crescimento com húmus $100 \%$ ), mas nesse caso, qualquer combinação de húmus + vermiculita resultou em crescimento similar ao uso do Plantmax ${ }^{\circledR}$. Portanto, o húmus +vermiculita foi considerado eficiente para a produção de mudas, sendo recomendado para a produção comercial de alface, tomate (e pimentão). A mistura de húmus a diferentes substratos, como por exemplo o Plantmax ${ }^{\circledR}$ e o pó de coco, também foi mais benéfica que o uso do húmus isolado para a produção de mudas de tomateiro "Santa Adélia" (Silveira et al. 2002).

Os resultados obtidos neste estudo são importantes para a produção comercial de mudas de tomateiro e alface, pois demonstraram que a casca de arroz, assim como o húmus de minhoca constituem-se materiais com potencial para serem utilizados como substratos para a produção de mudas, principalmente quando misturados com solo. O húmus, além de ser um composto rico em microrganismos, o que favorece a assimilação de nutrientes pelas raízes das plantas, apresenta a vantagem de possuir $\mathrm{pH}$ neutro, devido às minhocas utilizadas na minhocultura (E. andrei e E. fetida) apresentarem glândulas calcíferas, as quais elevam o $\mathrm{pH}$ do húmus, alterando conseqüentemente, a disponibilidade dos nutrientes sensíveis ao $\mathrm{pH}$ (Cabrera et al. 2007). A casca de arroz apresenta características favoráveis ao desenvolvimento das plantas, sendo considerada um condicionador de substrato. Proporciona boa oxigenação para as raízes, drenagem rápida e eficiente, elevado espaço de aeração ao substrato, relativa estabilidade de estrutura, baixa densidade e $\mathrm{pH}$ próximo à neutralidade (Mello 2006).

\section{AGRADECIMENTOS}

Ao apoio financeiro disponibilizado pela FIEX/UFSM, Departamento de Solos, ao CNPq pela bolsa de Mestrado e à CAPES pela bolsa de Doutorado.

\section{LITERATURA CITADA}

Andriollo, J. L. 1999. Fisiologia das culturas protegidas. UFSM, Santa Maria.

Aquino, A. M. \& E. M. Nogueira. 2001. Fatores limitantes da vermicompostagem de esterco suíno e de aves e influência da densidade populacional das minhocas na sua reprodução. Embrapa Agrobiologia Série Documentos No. 147, Seropédica. 
Brown, G. G., C. A. Edwards, \& L. Brussaard. 2004. How earthworms affect plant growth: burrowing into the mechanisms. Pp. 13-49. In: C. A. Edwards (Ed.). Earthworm ecology. St. Lucie Press, Boca Raton.

Cabrera, R. A. D., A. J. B. V. Azevedo-Filho \& S. M. Tsai. 2007. Perspectiva no manejo alternativo dos citros: Do viveiro ao campo. Pp. 525-532. In: G. G. Brown and C. Fragoso (Eds.). Minhocas na América Latina: biodiversidade e ecologia. Embrapa Soja, Londrina.

Couto, M., A. Wagner Júnior \& A. C. Quezada. 2003. Efeito de diferentes substratos durante a aclimatização de plantas micropropagadas do porta-enxerto mirabolano 29C (Prunus cerasifera EHRH.) em casa de vegetação. Revista Brasileira de Agrociência. 9: 125-128.

Diniz, K. A., S. T. M. R. Guimarães \& J. M. Q. Luz. 2006. Húmus como substrato para a produção de mudas de tomate, pimentão e alface. Bioscience Journal. 22: 63-70.

Edwards, C. A. 2004. The use of earthworms in the breakdown and management of organic wastes. Pp.327-354. In: C.A. Edwards (Ed.). Earthworm ecology. St. Lucie Press, Boca Raton.

Edwards, C. A. \& K. E. Fletcher. 1988. Interactions between earthworms and microorganisms in organic- matter breakdown. Agriculture Ecosystems and Enviroment. 24: 235-247.

Empresa Brasileira de Pesquisa Agropecuária. 1999. Sistema brasileiro de classificação de solos. Embrapa, Brasília.

Fagundes, C. A. A., F. F. Barbosa \& M. C. Elias. 2007. Arroz: colheu! Agora é secar para armazenar, conservar e comercializar. Lavoura Arrozeira. 55: 34-35.

Fernandez, M. R. 1993. Manual para laboratório de fitopatologia. Embrapa, Brasília.

Ferreira, D. F. 2000. Sistemas de análise estatística para dados balanceados. UFLA, Lavras.

Foletto, E. L., R. Hoffmann, R. S. Hoffmann, U. L. Jr. Portugal \& S. L. Jahn. 2005. Aplicabilidade das cinzas da casca de arroz. Química Nova. 28: 1055-1060.

Hand, P., W. A. Hayes, J. C. Frankland \& J. E. Satchell. 1988. The vermicomposting of cow slurry. Pedobiologia. 31: 199-209.

Mello, R. P. 2006. Consumo de água do lírio asiático em vaso com diferentes substratos. Dissertação de Mestrado em Engenharia Agrícola, Universidade Federal de Santa Maria, Santa Maria.

Menezes, J. F. O. G. 1998. Caracterização de diferentes substratos e seu efeito na produção de mudas de alface e couve-flor em ambiente protegido. Dissertação de Mestrado em Produção Vegetal, Universidade Federal de Pelotas, Pelotas.

Milec, A. T., R. M. D. Moraes, V. C. Xavier, D. C. Conceição, C. R. Mauch \& T. B. G. A. Morselli. 2007. Produção de mudas de couve brócolis em dois sistemas de irrigação utilizando substratos orgânicos. Revista Brasileira de Agroecologia. 2: 1483-1486.

Morselli, T. B. G. A., L. E. C. da Cruz, D. Pocai, A. H. Pich. 1997. Efeito de diferentes resíduos no comportamento de Eisenia foetida em estação quente: I. Eclosão. Científica Rural. 2: 45-49.

Oliveira, C.F.de. 2007. Safra 2006/07: produção mundial menor que consumo. Lavoura Arrozeira. 55: 5-11.

Pereira, E. W. L., C. M. S. B. Azevedo, J. Liberalino Filho, G. H. S. Nunes, J. E. Torquato \& B. R. Simões. 2005. Produção de vermicomposto em diferentes proporções de esterco bovino e palha de carnaúba. Caatinga. 18: 112-116.

Santos, C. M. R. 2000. Tratamentos pré-germinativos e produção de mudas de alface em cultivo hidropônico. Dissertação de Mestrado em Agronomia, Universidade Federal de Santa Maria, Santa Maria.

Silveira, E. B., V. J. L. B. Rodrigues, A. M. A. Gomes, R. I. R. Mariano \& J. C. P. Mesquita. 2002. Pó de coco como substrato para produção de mudas de tomateiro. Horticultura Brasileira. 20: 211-216.

Tedesco, M. J., S. J. Volkweiss \& H. Bohnem. 1995. Análises de solo, plantas e outros materiais. Departamento de Solos, UFRGS, Porto Alegre. 